\title{
Gamification and Advanced Technology to Enhance Motivation in Education
}

\author{
Rafael Molina-Carmona ${ }^{1,2, * \mathbb{D}}$ and Faraón Llorens-Largo ${ }^{1,2} \mathbb{D}$ \\ 1 Smart Learning Research Group, University of Alicante, 03690 Alicante, Spain; faraon.llorens@ua.es \\ 2 Cátedra Santander-UA de Transformación Digital, University of Alicante, 03690 Alicante, Spain \\ * Correspondence: rmolina@ua.es
}

Received: 25 May 2020; Accepted: 19 June 2020; Published: 23 June 2020

\begin{abstract}
The aim of this Special Issue is to compile a set of research works that highlight the use of gamification and other advanced technologies as powerful tools for motivation during learning. We have been fortunate to obtain a representative sample of the current research activity in this field.
\end{abstract}

Keywords: gamification; serious games; motivation

\section{Introduction}

Motivation is the driving force behind many human activities, in particular learning. Motivated students are ready to make a significant mental effort and use deeper and more effective learning strategies. Some of the fundamental attributes of learning strategies that enhance motivation are:

- Experimentation or learning by doing.

- Interactivity and immediate feedback.

- Allow and naturalize the error.

- Give control to the learner.

Numerous studies indicate that playing promotes learning, since when fun pervades the learning process, motivation increases, and tension is reduced. There is no doubt that the games comply with the four learning strategies that we have defined: playing is action and, therefore, experimentation and active learning; without interaction and continuous feedback, there is no game either; trial and error is the fundamental element thanks to which people learn to play and improve; and it is the player who maintains control of the game and who decides what actions to take at each step.

From our point of view, games can be very powerful tools in the improvement of learning processes from three different and complementary perspectives: as tools for teaching content or skills, as an object of the learning project itself, and as a philosophy to be taken into account when designing the training process. Each contributions presented in this Special Issue "Gamification and Advanced Technology to Enhance Motivation in Education" falls into one of these categories, that is to say, they all deal with the use of games or related technologies, and they all study how playing enhances motivation in education. In the following sections, we present the papers by establishing a thread that provides integrity to the Special Issue.

\section{Games as Teaching Tools}

The first group of papers consists of five contributions, in which the use of games to train students in different contents or skills is proposed. The first three papers present three serious games as tools for the teaching of subjects related to economic activity and the history of lunar explorations, in all 
cases with the motivation of the students as the main focus. In the fourth article, a serious game is complemented by other technological tools, in this case to develop the collaborative capacities of a population for the urban transformation of its environment. The last article in this section has a somewhat different, but related objective, as it attempts to analyze the attitude of teachers towards the use of games in the classroom.

The work of Teresa Rojo, Myriam González-Limón, and Asunción Rodríguez-Ramos [1] studies the use of a serious game, BugaMAP, for university teaching about insurance and evaluates its potential both objectively and subjectively. To do so, the authors propose a student opinion questionnaire evaluating the BugaMAP game (subjective evaluation); and the analysis of the patterns of the gamification of learning contained in the game (objective evaluation). Several variables are considered about aspects such as narrative, decision-making, short-term and long-term objectives, gifts for efforts, quick and clear responses, uncertainty, assistance, learning from decision impacts, and interaction with other players. Very valuable conclusions are obtained: a high satisfaction of the students with the knowledge acquired using fun and social interaction; the important role of the university professors and the company monitors; and the benefits of the company-university collaboration.

Zoltan Buzady and Fernando Almeida [2], for their part, present a serious game as a tool to acquire skills and abilities. FLIGBYis a serious game, which allows students to develop entrepreneurship skills in an immersive way based on real challenges that can be found in business environments. The authors propose a simple, but very effective quantitative approach to assess the success of FLIGBY adoption. They conclude that by using FLIGBY, students are able to train their skills in a wide range of domains like gathering information, motivating employees, training their emotional intelligence, and establishing social dynamics in a corporate environment. Two benefits are highlighted in the paper: (1) this informal teaching method based on a serious game allows students to increase technical skills in the field of management and entrepreneurship and also allows them to develop essential soft-skills; and (2) the authors have detected the arousal in other higher education institutions of the desire to include serious games as a complementary activity to formal teaching methods.

Creating a serious game about a mission to the moon and evaluating the use of Virtual Reality (VR) with respect to usability and engagement are the focus of Lizhou Cao, Chao Peng, and Jeffrey T. Hansberger's contribution [3]. In this work, they design and implement a serious VR game that immerses players into activities of lunar exploration missions in a virtual environment. They study the usability and engagement of the game through user experience in both VR and non-VR versions of the game, through the use of the Game Engagement Questionnaire (GEQ) and an interview questionnaire to measure levels of engagement. The experimental results show that the VR version of the lunar roving game took longer for participants to finish, but enhanced the game engagement and their motivation to learn the events of lunar exploration.

The work of Teodora Iulia Constantinescu and Oswald Devisch [4] also analyzes the use of serious games (and other technological tools), but in this case, with a different nuance. Specifically, the authors study how these tools enable collaboration between groups, in other words, how they contribute to training people to be able to collaborate, all within the context of actions to transform an urban area. To do so, the authors propose a conceptual framework for building capacities, in which the process and outputs collide with the ideas of choice, ability, and opportunity. The case study looks at one of the main commercial streets of the city of Ghent, Belgium (Vennestraat), and reflects on a set of enabling artifacts used to engage proprietors in the capacity-building process. This capacity-building process, characterized by the idea of space and capabilities, advances a critical viewpoint on issues related to participatory processes and gives practitioners a set of enabling tools to start a conversation about complex urban transformations.

Finally, in this section, Marta Martín-del-Pozo, Ana García-Valcárcel Muñoz-Repiso, and Azucena Hernández Martín [5] propose the creation of an attitude scale that primary school teachers present towards the use of video games for collaborative learning. In this case, a specific game is not used as a 
case study, but rather the opinion of the teachers is sought. The authors argue that for games to be successfully introduced into children's education, it is essential that teachers themselves are motivated to use them. Therefore, they propose to measure the attitude towards these new methodologies among the teachers, by creating an attitude scale towards collaborative learning with video games. They follow different methodological steps to make the scale construction possible, such as the analysis of items and the verification of their reliability, resulting in a rigorous attitude scale of 33 items, with high reliability, so that the measurement instrument can be considered as useful and valid.

\section{Games as Learning Objects}

Games can also be the object of the learning process. Although this aspect is better suited to some disciplines than others, there are more and more areas in which the study of games is not only interesting, but also convenient. This is undoubtedly true in the case of computer engineering and similar fields that can use video games as projects to be developed by students. A different case, but also very interesting, is the analysis of games to study aspects that are an intrinsic part of video games, such as their interaction, usability, visual design, or the artificial intelligence of their characters. This is the case of the work of Pedro C. Santana-Mancilla, Miguel A. Rodriguez-Ortiz, Miguel A. Garcia-Ruiz, Laura S. Gaytan-Lugo, Silvia B. Fajardo-Flores, and Juan Contreras-Castillo [6], which studies aspects of Human-Computer Interaction (HCI) through the analysis of video games. From our point of view, this paper makes two key contributions: a proposal for using the design and evaluation of computer games as a learning tool to teach HCI to undergraduate students; and the empirical validation of this proposal to explore students' attitudes with the aim to understand if the students believe that using video games allows them to learn higher education skills. The experimental results of the validation process indicate that using video games as teaching method provides the students with the HCI skills (psychology of everyday things, involving users, task-centered system design, models of human behavior, creativity and metaphors, and graphical screen design), and more importantly, they have a positive perception of the efficacy of the use of video game design in a higher education course.

\section{Games as a Design Philosophy: Gamification}

Finally, games can serve as inspiration for the development of teaching methodologies that, without being exactly games, incorporate the philosophy of games, both in their design and in their learning objectives. This is the case of gamification, which has been gaining momentum in recent years. Gamification consists of applying the principles of video game design, the use of mechanics and the elements of a game in any process, beyond the context of video games. The aim is to take advantage of both the psychological predisposition of people to participate in games and the quality of the game to motivate and improve the behavior of the participants. Precisely for this reason, due to its motivating nature, it is the subject of analysis on four of the contributions in this Special Issue, each with a different point of view. These include a review of the literature on the effects of gamification on online learning, a case study of gamification in a Massive Online Open Course (MOOC), a guide to the gamification of learning activities, and a methodology for designing assessment rubrics inspired by the principles of gamification.

A good way to understand a topic is to review the corresponding literature. That is what Alessandra Antonaci, Roland Klemke, and Marcus Specht [7] do in their systematic review of the literature on the effects of gamification in online learning environments. In this study, they identify 24 gamification elements that, combined, produce empirical effects on users' behavior in online learning in six areas: performance, motivation, engagement, attitude towards gamification, collaboration, and social awareness. This contribution is significant, and it is reinforced by the fact that the other papers presented in this Special Issue are in one of these six areas. The findings of this literature review point out that gamification and its application in online learning and in particular in MOOCs are still 
a young field, lacking empirical experiments and evidence, with a tendency of using gamification mainly as external rewards.

The second article in this section, by Oriol Borrás-Gené, Margarita Martínez-Núñez, and Luis Martín-Fernández [8], fills part of the gap detected in the previous literature review, presenting a particular case of the introduction of gamification elements in an MOOC and its associated Virtual Learning Community (VLC), together with a study on the fun and engagement that are achieved through gamification. The aim of this research is to find out whether, through the application in one MOOC, with a connectivism approach, of various gamification techniques, which increase motivation and fun, it is possible to achieve a greater engagement in terms of participation and generate a habit in the use of the VLC. To do so, a satisfaction survey, based on the validated SEEQsurvey, is conducted. The results show an increment of active participation and engagement within the MOOC community in the form of content creation and, especially, greater interaction and the generation of a habit so that the activity continues once the edition of the MOOC is finished.

The contribution of Francisco J. Gallego-Durán, Carlos J. Villagrá-Arnedo, Rosana Satorre-Cuerda, Patricia Compañ-Rosique, Rafael Molina-Carmona, and Faraón Llorens-Largo [9] emphasizes the relationship between video games and gamification. The authors consider that if there are video games that entertain and engage players in a very remarkable way, it is interesting to study what the design principles of these games are to try to bring them into a gamification process. Although there is no consensus on these design principles and much of the success of some video games is due to the experience and know-how of game designers, it is possible to establish guidelines that can help design more effective, challenging, and engaging gamification experiences. The guidelines are presented in the form of a rubric for educators and researchers to start working in gamification without previous experience in game design. This rubric decomposes the continuous space of game design into a set of ten discrete characteristics, based on the previous design experience of the authors, compared and contrasted with the literature, and empirically tested with some example games and gamified activities. As a consequence, a better understanding of the strengths and weaknesses of gamification and some tips to help in the design or improvement of activities are obtained.

The last article in the Special Issue is by Daniel Corona Martínez and José Julio Real García [10]. In their work, gamification is used as an inspiration to develop assessment rubrics. They make a methodological proposal to design educational rubrics to assess students' experiences of the active methodologies in secondary education. Their goal is to design better educational rubrics based on Malone's game theory and theoretical models of game design. As a main contribution, they propose a translation from game theory ideas into didactical concepts that can be transcribed and used in a didactical approach. As a consequence, they propose five main concepts that appear constantly and repeatedly during Malone's argumentation: challenge, curiosity, fantasy, design, and environment. These concepts are used to define the rubric, but instead of a simple translation, the authors apply a didactic and educational filter prior to proceeding, resulting in the five items that are part of the rubric: achievement, originality, motivation, design and quality, and relationships and time management. The resulting evaluation rubric includes a holistic approach to all different aspects related to the evaluation for active methodologies in a secondary education environment.

\section{Conclusions}

Playing is a pleasant, motivating human activity from which much can be learned. Teachers can take advantage of the characteristics of games to impregnate their teaching methodologies and motivate their students. The interactive features of the games, the action, and the speed strengthens the neurons and links that are involved in the correct prediction by means of endorphins and dopamine, giving the player the sensation commonly known as fun. This is how learning and intrinsic motivation occur.

Motivation is one of the key aspects of good instructional design and becomes more important as the learner takes ownership of the process. In traditional teaching, the teacher in the classroom can react to the attitudes of the students. However, in online teaching, the interaction between teacher and 
students and students among themselves becomes less intense, and the interaction of students with learning resources becomes more important. In this sense, designing the learning experience with the aim of motivating the students will serve both face-to-face and remote teaching.

With the conviction that games, gamification, and other related technologies have this motivating potential, the call for participation in this Special Issue was made. The selected articles present innovative ideas, models, approaches, technologies, reviews, and case studies that contribute to creating a publication of high interest. The Guest Editors of this Special Issue would like to thank the authors for their great work, which enriches research on gamification and advanced technology to enhance motivation in education.

Author Contributions: Conceptualization, R.M.-C. and F.L.-L.; writing, original draft preparation, R.M.-C. and F.L.-L.; writing, review and editing, R.M.-C. and F.L.-L. All authors read and agreed to the published version of the manuscript.

Acknowledgments: The Special Issue Editors would like to acknowledge the reviewers for their essential contribution to the quality of the papers.

Conflicts of Interest: The authors declare no conflict of interest.

\section{References}

1. Rojo, T.; González-Limón, M.; Rodríguez-Ramos, A. Company-University Collaboration in Applying Gamification to Learning about Insurance. Informatics 2019, 6, 42, doi:10.3390/informatics6030042.

2. Buzady, Z.; Almeida, F. FLIGBY - A Serious Game Tool to Enhance Motivation and Competencies in Entrepreneurship. Informatics 2019, 6, 27, doi:10.3390/informatics6030027.

3. Cao, L.; Peng, C.; Hansberger, J.T. Usability and Engagement Study for a Serious Virtual Reality Game of Lunar Exploration Missions. Informatics 2019, 6, 44, doi:10.3390/informatics6040044.

4. Constantinescu, T.I.; Devisch, O. Serious Games, Mental Images, and Participatory Mapping: Reflections on a Set of Enabling Tools for Capacity Building. Informatics 2020, 7, 7, doi:10.3390/informatics7010007.

5. Martín-del Pozo, M.; García-Valcárcel Muñoz-Repiso, A.; Hernández Martín, A. Video Games and Collaborative Learning in Education? A Scale for Measuring In-Service Teachers' Attitudes towards Collaborative Learning with Video Games. Informatics 2019, 6, 30, doi:10.3390/informatics6030030.

6. Santana-Mancilla, P.C.; Rodriguez-Ortiz, M.A.; Garcia-Ruiz, M.A.; Gaytan-Lugo, L.S.; Fajardo-Flores, S.B.; Contreras-Castillo, J. Teaching HCI Skills in Higher Education through Game Design: A Study of Students' Perceptions. Informatics 2019, 6, 22, doi:10.3390/informatics6020022.

7. Antonaci, A.; Klemke, R.; Specht, M. The Effects of Gamification in Online Learning Environments: A Systematic Literature Review. Informatics 2019, 6, 32, doi:10.3390/informatics6030032.

8. Borrás-Gené, O.; Martínez-Núñez, M.; Martín-Fernández, L. Enhancing Fun Through Gamification to Improve Engagement in MOOC. Informatics 2019, 6, 28, doi:10.3390/informatics6030028.

9. Gallego-Durán, F.J.; Villagrá-Arnedo, C.J.; Satorre-Cuerda, R.; Compañ-Rosique, P.; Molina-Carmona, R.; Llorens-Largo, F. A Guide for Game-Design-Based Gamification. Informatics 2019, 6, 49, doi:10.3390/informatics6040049.

10. Corona Martínez, D.; Real García, J. Using Malone's Theoretical Model on Gamification for Designing Educational Rubrics. Informatics 2019, 6, 9, doi:10.3390/informatics6010009.

( 2020 by the authors. Licensee MDPI, Basel, Switzerland. This article is an open access article distributed under the terms and conditions of the Creative Commons Attribution (CC BY) license (http:// creativecommons.org/licenses/by/4.0/). 